\title{
Fiscal Federalism and Economic Growth
}

\author{
by \\ Jan K. Brueckner \\ Department of Economics \\ University of California, Irvine \\ 3151 Social Science Plaza \\ Irvine, CA 92697 \\ e-mail: jkbrueck@uci.edu
}

October 2005

\begin{abstract}
This paper uses an endogenous-growth model with overlapping generations to explore the connection between fiscal federalism and economic growth. The analysis shows that federalism, which allows public-good levels to be tailored to suit the differing demands of young and old consumers, who live in different jurisdictions, increases the incentive to save. This stronger incentive in turn leads to an increase in investment in human capital, and a byproduct of this higher investment is faster economic growth.
\end{abstract}




\section{Fiscal Federalism and Economic Growth}

by

Jan K. Brueckner*

\section{Introduction}

Fiscal federalism, under which provision of public goods is decentralized to subnational governments, allows public consumption levels to be tailored to suit the preferences of a heterogeneous population. This beneficial outcome, first emphasized by Tiebout (1956) in a classic paper, is achieved via sorting of individuals into demand-homogeneous jurisdictions, each of which provides a different amount of the public good. The drawbacks of federalism, which have also been noted in the literature, include the sacrifice of scale economies due to smaller jurisdiction sizes (Oates, 1972, Alesina and Spoalore, 1997), losses from interjurisdictional tax competition when government revenue comes from taxation of a mobile tax base (Brueckner, 2004), and failure to properly account for public-good spillovers across jurisdictions (Oates, 1972, and Besley and Coate, 2003). ${ }^{1}$

A recent empirical literature explores a different effect of fiscal federalism by studying the impact of decentralized public spending on economic growth. This inquiry was inspired in part by the work of Oates (1993), who conjectured that better targeting of growth-enhancing infrastructure investment under federalism could raise an economy's growth rate. In a related argument, Davoodi and Zou (1996) show that, if national and subnational public goods enter as separate inputs in a Cobb-Douglas aggregate production function, then growth maximization requires an appropriate degree of fiscal decentralization, with the subnational spending share matching its Cobb-Douglas exponent. The initial contributions to the empirical literature, which include Davoodi and Zou (1998), Zhang and Zou (1998), and Xie, Zou and Davoodi (1999), disconfirm Oates' conjecture by finding a negative connection between fiscal decentralization and growth, a result that could be consistent with excessive decentralization under the Davoodi-Zou framework. However, the more-recent papers Lin and Liu (2000), Akai and Sakata (2002), Stansel (2005) and Iimi (2005) all find a positive relationship between 
decentralization and growth, suggesting that Oates may have been right after all.

Despite this intense empirical focus, little additional theoretical effort has been devoted to studying the decentralization-growth nexus. The present paper is intended to remedy this omission in the literature. The analysis builds on the earlier work of Brueckner (1999), who used an overlapping generations (OLG) model to show that, in a dynamic context, federalism affects the incentive to save. It does so by replacing a common tax burden, associated with uniform national provision of the public good $z$, with head-tax burdens that differ between young and old consumers, who live in separate jurisdictions where $z$ is provided at different levels in response to age-dependent demands. Federalism thus alters the time path of after-tax income over the life cycle, thereby affecting the economy's level of saving.

Because Brueckner's analysis relied on the traditional Diamond (1965) OLG model, this difference in saving altered the economy's steady-state capital intensity without affecting its growth rate, except in the transition between the "unitary" system (where a common $z$ level is provided nationally) and a federalist system. To generate results more closely linked to the empirical literature, the present paper makes use of an endogenous-growth model with overlapping generations, where the choice between the unitary and federalist systems affects the economy's growth rate. The analysis adapts the OLG model of Yakita (2003), where consumers invest in human capital while young to enhance their earning power in old age. While education thus plays a key role in the analysis, the public good itself is assumed to be unrelated to the educational process, instead representing goods such as health services, transportation, public safety, recreation, etc. Relaxation of this assumption is left for future work.

In common with other endogenous-growth models, a key feature of Yakita's framework is rising income over the life cycle, a consequence of the work-time sacrifice required for schooling while young combined with the payoff to this schooling in old age. Given this income pattern, the public-good demands of the young and old are, respectively, low and high. While these demands are fulfilled under the federalist system, where the young and old live in separate jurisdictions, a unitary system provides a common, intermediate level of $z$. As a result, $z$ rises for the young and falls for the old in moving from federalism to a unitary system, and the head 
taxes paid by the two age groups move in step. But viewed from a single individual's life-cycle perspective, these changes reduce after-tax income when young while raising it when old. The resulting alteration in the time path of income then reduces the incentive to save.

The lower saving incentive under the unitary system disrupts equilibrium in the market for physical capital, requiring an adjustment that restores some of the lost savings. This adjustment comes partly from a reduction in investment in human capital, achieved by a decline in the share of a young person's time devoted to schooling. Since this change raises income for the young and lowers it for the old, the result is an offsetting increase in the incentive to save. But since the economy's growth rate depends positively on the extent of investment in human capital, moving to a unitary system ultimately depresses growth.

The analysis thus suggests that faster economic growth may be an additional benefit of fiscal federalism. However, in contrast to the conceptual work mentioned above, where output and growth are directly tied to the provision of public goods, this result emerges from a model in which federalism offers nothing more than the ability to tailor $z$ consumption to suit different demands. The model's link between federalism and growth is thus quite indirect.

Like all of the Tiebout literature, the present model can be criticized on the grounds that its sorting assumption, under which the federalist population divides into demand-homogeneous, young and old jurisdictions, is unrealistic. Despite the criticisms of various authors (see Strumpf and Rhode (2003) for a recent contribution), casual empiricism nevertheless reveals at least a weak tendency toward jurisdictional homogeneity like that presumed in the analysis. In any case, like all models in the Tiebout tradition, the present one can be viewed as depicting an idealized world while identifying a savings-induced link between federalism and growth that may have more general relevance.

The plan of the paper is as follows. Section 2 introduces the model and characterizes the steady-state equilibrium under fiscal federalism. Section 3 considers the unitary case, and section 4 compares the federalist and unitary steady state solutions. Section 5 offers conclusions. 


\section{The Model and the Federalist System}

The analysis relies on the model of Yakita (2003), modified to include a public good. In the model, each consumer lives for two periods. When young, the consumer invests a portion of his fixed time allotment in schooling, with the remainder spent working. In old age, all time is devoted to work, with labor productivity having been enhanced by earlier schooling. In each period, the consumption bundle consists of a numéraire private good $x$ and a public good $z$, whose cost is financed by a head tax. When young, the consumer saves a portion of his income by investing in physical capital.

The consumption variables in the model are indexed both by a time subscript and by a superscript indicating the consumer's generation, or date of birth. Thus, $x_{t}^{t}$ denotes the time- $t$ consumption of individuals born at $t$, or equivalently, the consumption while young of generation $t$ (the one born at $t$ ). Similarly, $x_{t+1}^{t}$ indicates the time- $(t+1)$ consumption of individuals born at $t$, or equivalently, the consumption while old of generation $t$. Analogous definitions apply to the public consumption levels $z_{t}^{t}$ and $z_{t+1}^{t}$.

Generation $t$ has a human capital level of $h_{t}^{t}$ when young and $h_{t+1}^{t}$ when old. These levels are connected by the relationship

$$
h_{t+1}^{t}=\phi\left(e_{t}\right) h_{t}^{t}
$$

where $e_{t} \in[0,1]$ is the share of time devoted to schooling for young individuals at time $t$. The function $\phi$ satisfies $\phi(0)=1$, indicating that human capital remains constant over the life cycle if no schooling is undertaken, as well as $\phi^{\prime}>0$ and $\phi^{\prime \prime}<0$, with the latter assumption indicating diminishing returns to schooling. Note that these assumptions yield $\phi\left(e_{t}\right)>1$ for $e_{t}>0$. In addition, note that if $z$ were an education-related public good, then $z_{t}^{t}$ would be an argument of $\phi$ along with $e_{t}$, greatly increasing the complexity of the analysis. Treatment of this case could be a subject for future research.

While Yakita assumes that human capital is transmitted intergenerationally with decay, the simpler assumption that young individuals fully inherit the human capital of their (old) 
parents is used here instead without loss of generality. This assumption is written

$$
h_{t}^{t}=h_{t}^{t-1}
$$

which says that the human capital of generation $t$ when young equals the human capital of generation $t-1$ when old.

Letting $w_{t}$ denote the time- $t$ wage and $s_{t}$ denote the savings of young consumers at time $t$, the budget constraints for a member of generation $t$ while young and old are, respectively,

$$
\begin{aligned}
x_{t}^{t}+c z_{t}^{t}+s_{t} & =w_{t}\left(1-e_{t}\right) h_{t}^{t} \\
x_{t+1}^{t}+c z_{t+1}^{t} & =w_{t+1} h_{t+1}^{t}+s_{t}\left(1+r_{t+1}\right) .
\end{aligned}
$$

Note that the consumer's labor supply per unit of time is equal to his human capital level, and that $r_{t+1}$ gives the interest rate prevailing at time $t+1$. Note also that the cost per capita per unit of the public good is equal to $c$, with the cost recovered via a head tax. Other tax schemes are considered below.

With a single consumption good $x$, Yakita assumes that utility takes the logarithmic form $\log x$ in each period, with a discount rate of $\rho$. Generalizing these assumptions to the present two-good case, lifetime utility for generation $t$ is equal to

$$
\alpha \log x_{t}^{t}+\beta \log z_{t}^{t}+\frac{1}{1+\rho}\left[\alpha \log x_{t+1}^{t}+\beta \log z_{t+1}^{t}\right]
$$

In maximizing utility, the optimal $z$ 's are first chosen conditional on $s_{t}$ and $e_{t}$. The $z$ solutions are substituted into (5), and $s_{t}$ is then chosen conditional on $e_{t}$. Finally, $e_{t}$ is set optimally.

Under the federalist system, the individuals alive at a given time are separated into young and old jurisdictions, each with a distinct public-good level. Therefore, the $z$ levels in (5) can be set to maximize generation t's utility levels in each period of its life subject to (3) and (4). This maximization yields

$$
z_{t}^{t}=\frac{\beta}{(\alpha+\beta) c}\left[w_{t}\left(1-e_{t}\right) h_{t}^{t}-s_{t}\right]
$$




$$
z_{t+1}^{t}=\frac{\beta}{(\alpha+\beta) c}\left[w_{t+1} \phi\left(e_{t}\right) h_{t}^{t}+\left(1+r_{t+1}\right) s_{t}\right]
$$

where (1) is used to eliminate $h_{t+1}^{t}$. In a steady-state equilibrium, where the wage $w$ is constant over time, inspection of (6) and (7) shows that, for any $e_{t}>0, z_{t}^{t}<z_{t+1}^{t}$ holds (recall $\phi>1$ ). Thus, public-good consumption rises over the life cycle, reflecting the growth of income due to human capital investment. Note that this conclusion relies on the fact that saving is positive, which is required for the capital stock to be held by the population, as discussed below.

It is also true that the public-good consumption of the old individuals alive at time $t$, who belong to generation $t-1$, exceeds the consumption of the young at $t$. Lagging (7) by one period and recalling that $\phi\left(e_{t-1}\right) h_{t-1}^{t-1}=h_{t}^{t-1}$ yields

$$
z_{t}^{t-1}=\frac{\beta}{(\alpha+\beta) c}\left[w_{t} h_{t}^{t-1}+\left(1+r_{t}\right) s_{t-1}\right]
$$

But since $h_{t}^{t-1}=h_{t}^{t}$ by (2) (the human capital level of the old at $t$ is passed on to their children), it follows that (8) exceeds (6). This relationship, which holds both in and out of a steady state, implies that at any given time, jurisdictions inhabited by the young provide lower public-good levels than those inhabited by the old.

To derive the optimal level of saving, (6) and (7) are substituted along with corresponding solutions for the $x$ 's into (5). Lifetime utility is then proportional to

$$
\log \left[w_{t}\left(1-e_{t}\right) h_{t}^{t}-s_{t}\right]+\frac{1}{1+\rho} \log \left[w_{t+1} \phi\left(e_{t}\right) h_{t}^{t}+\left(1+r_{t+1}\right) s_{t}\right]
$$

an expression identical to the consumer objective function in Yakita's single-good model. Maximizing (9) with respect to $s_{t}$ then yields

$$
s_{t}=\frac{1}{2+\rho} w_{t}\left(1-e_{t}\right) h_{t}^{t}-\frac{1+\rho}{2+\rho} \frac{w_{t+1} \phi\left(e_{t}\right) h_{t}^{t}}{1+r_{t+1}} .
$$

This saving solution is the same as Yakita's, which shows that introduction of a public good has no effect in his model provided that preferences take the Cobb-Douglas form and $z$ can be 
tailored to suit the different demands of young and old individuals. As will be seen below, this equivalence disappears under the unitary system, where a common public-good level must be provided to the young and old at each time $t$.

Finally, $e_{t}$, the share of time devoted to schooling when young, is chosen to maximize (9). After substituting the saving solution into the first-order condition for $e_{t}$, the following condition emerges:

$$
-w_{t}+\frac{w_{t+1} \phi^{\prime}\left(e_{t}\right)}{1+r_{t+1}}=0 .
$$

This condition says that $e_{t}$ is optimal when the loss from additional time spent on schooling while young $\left(-w_{t}\right)$ equals the present value of the gain when old.

On the production side of the model, capital is combined with a labor input, measured by the human capital of workers, to produce $x$ under constant returns. The intensive form of the production function given by $f(k)$, where $k$ is capital per unit of labor input. Capital is assumed to fully depreciate each period, so that its cost, inclusive of the return to investors, is $1+r$. As usual, the conditions $f^{\prime}\left(k_{t}\right)=1+r_{t}$ and $w_{t}=f\left(k_{t}\right)-k_{t} f^{\prime}\left(k_{t}\right) \equiv w\left(k_{t}\right)$ then hold.

The economy's capital stock in each period must equal total savings from the previous period. To satisfy this requirement, the economy must generate positive savings even though human capital investment leads to a rising time path of income, an outcome achieved by adjustment of the interest rate. To derive the relevant equilibrium condition, let population growth be absent, with the size of each generation normalized to unity. Then, labor supply at time $t+1$ is equal to $L_{t}=\left(1-e_{t+1}\right) h_{t+1}^{t+1}+h_{t+1}^{t}=\left(1-e_{t+1}\right) h_{t+1}^{t}+h_{t+1}^{t}=\left(2-e_{t+1}\right) \phi\left(e_{t}\right) h_{t}^{t}$, using (1) and (2). Multiplying this expression by $k_{t+1}$ thus gives the economy's total capital stock at $t+1$, denoted $K_{t+1}$. But the resulting expression, $\left(2-e_{t+1}\right) \phi\left(e_{t}\right) h_{t}^{t} k_{t+1}$ must equal total savings at $t$, which is given by the $s_{t}$ solution in (8), recalling the unitary size of each generation.

The steady-state version of this equilibrium condition is relevant for the analysis. In a steady state, capital per worker, and hence the wage and interest rate, are constant over time, as is the time devoted to schooling. The level of human capital, however, grows at the constant proportional rate of $\phi(e)$, where $e$ represents a steady-state value. Letting $k$ denote capital 
per unit labor input in the steady state and using (10), the equality $s_{t}=\left(2-e_{t+1}\right) \phi\left(e_{t}\right) h_{t}^{t} k_{t+1}$ thus reduces to

$$
B^{f}(k, e) \equiv \frac{1}{2+\rho} w(k)(1-e)-\frac{1+\rho}{2+\rho} \frac{w(k) \phi(e)}{f^{\prime}(k)}-(2-e) \phi(e) k=0
$$

in the steady state. Note that $h_{t}^{t}$ cancels and that $f^{\prime}(k)$ replaces $1+r_{t+1}$ in (10) (the $B$ function is a shorthand for the long expression in (12), and the $f$ superscript denotes the federalist case).

Eq. (12) provides one condition to solve for the two unknowns, $k$ and $e$, and the other condition comes from the steady-state version of (11). Cancelling the constant wage rate and eliminating the interest rate, (11) reduces to the condition

$$
f^{\prime}(k)-\phi^{\prime}(e)=0
$$

in the steady state. This condition says that the returns to physical and human capital are equal.

It is easily seen that (13) generates an upward sloping curve in $(k, e)$ space, denoted the $N$ locus. As explained further below, Yakita shows that the curve generated by (12), denoted the $B^{f}$ locus, is downward sloping when a condition ensuring saddle-path stability of the steady state is satisfied. In this case, the steady-state equilibrium, given by the intersection of the locii, is unique. The equilibrium is illustrated in Figure 1, which also contains a locus relevant to the unitary case considered below.

Before proceeding, it is useful investigate the growth rates of key variables in the model. Using the above solution for $L_{t}$, the proportional growth rate of labor supply equals

$$
\frac{L_{t+1}}{L_{t}}=\frac{(2-e) \phi(e) h_{t+1}^{t+1}}{(2-e) \phi(e) h_{t}^{t}}=\frac{h_{t+1}^{t+1}}{h_{t}^{t}}=\frac{h_{t+1}^{t}}{h_{t}^{t}}=\phi(e),
$$

naturally matching the growth rate of human capital. Since capital per unit of labor $(k)$ is constant, it follows that total capital also grows at the proportional rate of $\phi(e)$. By constant returns, $x$ output, as well as output per capita, then grow at this same rate. 


\section{The Unitary System}

Under the unitary system, a common public-good level $z_{t}$ is provided to the young and old individuals alive at $t$. Although the population is now contained in a single jurisdiction rather than being divided into young and old jurisdictions, $z$ 's cost per capita is assumed to remain at $c$, reflecting the assumption that the good is a publicly produced private good.

The level of $z_{t}$ is chosen according to a weighted average of the preferences of the young and old. Letting MRS denote the marginal rate of substitution between $z$ and $x$, the condition for choice of $z_{t}$ is

$$
\theta \operatorname{MRS}_{t}^{t}+(1-\theta) \mathrm{MRS}_{t}^{t-1}=c
$$

where $\theta \in(0,1)$. Note that, in contrast to (6) and (7), which apply to the young and old members of a given generation, (15) involves the young and old of different generations, whose preferences are aggregated to determine public-good provision at time $t$. Observe also that, while (15) corresponds to the Samuelson condition when $\theta=1 / 2$, the equation can capture other decision rules where one group exerts political power disproportionate to its population share.

Using (5) to compute MRS, and using the budget constraint (3) and the lagged version of (4) to eliminate the $x$ 's, (15) becomes

$$
\theta \frac{\beta\left(w_{t}\left(1-e_{t}\right) h_{t}^{t}-s_{t}-c z_{t}\right)}{\alpha z_{t}}+(1-\theta) \frac{\beta\left(w_{t} h_{t}^{t-1}+\left(1+r_{t}\right) s_{t-1}-c z_{t}\right)}{\alpha z_{t}}=c .
$$

Solving (16) for $z_{t}$ then yields

$$
z_{t}=\frac{\beta}{(\alpha+\beta) c}\left[\theta\left(w_{t}\left(1-e_{t}\right) h_{t}^{t}-s_{t}\right)+(1-\theta)\left(w_{t} h_{t}^{t-1}+\left(1+r_{t}\right) s_{t-1}\right)\right]
$$

Referring to (6) and (8), it is apparent that the solution in (17) is a weighted average of the time- $t$ young and old public-good levels under the federalist system. In other words,

$z_{t}=\theta z_{t}^{t}+(1-\theta) z_{t}^{t-1}$. Recalling that $z_{t}^{t-1}>z_{t}^{t}$ holds, it follows that, for given values of the $e, h$, and $s$ variables, the unitary $z_{t}$ is larger than the public-good level of the young 
under federalism at time $t\left(z_{t}>z_{t}^{t}\right)$ and smaller than the federalist level of the old at time $t$ $\left(z_{t}<z_{t}^{t-1}\right)$.

To find the level of saving under the unitary system, it is useful to first solve for saving conditional on the public-good levels and then substitute the relevant $z$ solutions using (17). This conditional saving solution can be generated by simply subtracting public-good costs from the period incomes in the previous saving solution in (10), which yields

$$
s_{t}=\frac{1}{2+\rho}\left[w_{t}\left(1-e_{t}\right) h_{t}^{t}-c z_{t}\right]-\frac{1+\rho}{2+\rho} \frac{w_{t+1} \phi\left(e_{t}\right) h_{t}^{t}-c z_{t+1}}{1+r_{t+1}} .
$$

Then, substituting into (18) the $z_{t}$ solution from (17) and the $z_{t+1}$ solution found by updating (17) one period yields

$$
\begin{aligned}
& s_{t}=s_{t}^{f}-\frac{\beta}{(1+\rho)(\alpha+\beta)}\left[\theta\left(w_{t}\left(1-e_{t}\right) h_{t}^{t}-s_{t}\right)+(1-\theta)\left(w_{t} h_{t}^{t-1}+\left(1+r_{t}\right) s_{t-1}\right)\right]+ \\
& \frac{\beta(1+\rho)}{\left(1+r_{t+1}\right)(2+\rho)(\alpha+\beta)}\left[\theta\left(w_{t+1}\left(1-e_{t+1}\right) h_{t+1}^{t+1}-s_{t+1}\right)+(1-\theta)\left(w_{t+1} h_{t+1}^{t}+\left(1+r_{t+1}\right) s_{t}\right)\right],
\end{aligned}
$$

where $s_{t}^{f}$ is the federalist saving solution from (10). To express all the $h$ 's in (18) in terms of $h_{t}^{t}$, the relationships $h_{t}^{t}=h_{t}^{t-1}$ and $h_{t+1}^{t+1}=h_{t+1}^{t}=\phi\left(e_{t}\right) h_{t}^{t}$ are used. In addition, focusing on the steady state, where saving grows at the proportional rate $\phi(e)$, allows all the saving variables in (18) to be expressed in terms of $s_{t}$. In particular, $s_{t+1}=\phi(e) s_{t}$ and $s_{t-1}=s_{t} / \phi(e)$.

Making these substitutions and solving (18) for $s_{t}$ in the steady state yields

$$
s_{t}=\frac{\Omega}{2+\rho} w(k)(1-e) h_{t}^{t}-\Phi \frac{1+\rho}{2+\rho} \frac{w(k) \phi(e) h_{t}^{t}}{f^{\prime}(k)},
$$

where

$$
\Omega=\frac{(2+\rho) \Delta}{\Delta+(1+\rho) \Gamma}
$$




$$
\begin{aligned}
\Phi & =\frac{(2+\rho) \Gamma}{\Delta+(1+\rho) \Gamma} \\
\Delta & =1+\frac{\theta \beta}{\alpha+\beta}\left(\frac{1+\rho}{f^{\prime}(k)} \phi(e)-1\right) \\
\Gamma & =1+\frac{(1-\theta) \beta}{\alpha+\beta}\left(\frac{f^{\prime}(k)}{1+\rho} \frac{1}{\phi(e)}-1\right) .
\end{aligned}
$$

Using (19), the savings equilibrium condition (12) is rewritten as

$$
B^{u}(k, e) \equiv \frac{\Omega}{2+\rho} w(k)(1-e)-\Phi \frac{1+\rho}{2+\rho} \frac{w(k) \phi(e)}{f^{\prime}(k)}-(2-e) \phi(e) k=0
$$

( $B$ 's superscript refers to the unitary case). Like (12), this condition generates a curve in $(k, e)$ space, which is denoted the $B^{u}$ locus. It can be shown that the previous steady-state condition for choice of $e$, given by (13), continues to apply, so that the previous $N$ locus in Figure 1 remains relevant.

\section{Comparing the Federalist and Unitary Steady States}

\subsection{Main analysis}

To compare the steady states under federalism and the unitary system, the positions of $B^{f}$ and $B^{u}$ locii in Figure 1 must be compared. To do so, the magnitudes of the $\Omega$ and $\Phi$ terms in (24), which account for the difference between the previous equilibrium condition (12) and (24), must be evaluated. The following result emerges:

Lemma. On the $B^{u}$ locus, the inequalities $0<\Omega<1$ and $\Phi>1$ are satisfied.

Proof: The difference between the first two terms in $B^{u}(k, e)$ from $(24)$ is necessarily positive on the $B^{u}$ locus, where $(24)$ is satisfied, which means that $(1-e) \Delta-(1+\rho) \phi(e) \Gamma / f^{\prime}(k)>0$ must hold. But substituting from (22) and (23), this requirement reduces to

$$
-e+\left(1-\frac{1+\rho}{f^{\prime}(k)} \phi(e)\right)\left[1-\frac{\beta}{\alpha+\beta}((1-e) \theta+(1-\theta))\right]>0
$$


This condition implies $1-\left((1+\rho) / f^{\prime}(k)\right) \phi(e)>0$, which in turn yields $\Delta<1$ from $(22)$ and $\Gamma>1$ from (23). Inspection of (22) shows also that $\Delta$ is positive, implying $\Omega>0$. Further manipulations using (20) and (21) show that the inequalities $\Omega<1$ and $\Phi>1$ are equivalent to $\Delta<\Gamma$, establishing the lemma.

To develop the implications of the lemma, consider the previous equilibrium condition (12), which defines the $B^{f}$ locus. Yakita shows that $B_{e}^{f}<0$ holds along the $B^{f}$ locus and that $B_{k}^{f}<0$ holds as well provided that a stability condition is satisfied (subscripts here denote partial derivatives). ${ }^{2}$ These facts imply that the $B^{f}$ locus is downward sloping, which in turn implies uniqueness of the steady-state equilibrium under federalism, as noted above. The negativity of these derivatives also means that $B^{f}(k, e)>0$ holds at points lying immediately to the southwest of the $B^{f}$ locus, including points in this area that lie on the $N$ locus. But given uniqueness of the equilbrium, $B^{f}(k, e)$ must then be positive at all points on the $N$ locus lying to the southwest of the $B^{f}$ locus. Otherwise, another point would exist on this portion of the $N$ locus where $B^{f}(k, e)$ equals zero, yielding an additional equilibrium. Similarly, $B^{f}(k, e)$ must be negative on the $N$ locus everywhere to the northeast of the $B^{f}$ locus.

Using these conclusions, the following key result can be established:

Proposition 1. In any steady-state equilibrium under the unitary system, $k$ and e are lower than in the federalist equilibrium. With the proportional rate of economic growth given by $\phi(e)$, it follows that growth is faster under federalism than under the unitary system.

Proof: Since $\Omega<1$ and $\Phi>1$ hold by the lemma along the $B^{u}$ locus, it follows that $B^{f}(k, e)>$ $B^{u}(k, e)$ also holds on that locus. Therefore, at a unitary steady state, where the $B^{u}$ locus intersects the $N$ locus and $B^{u}(k, e)=0$, the inequality $B^{f}(k, e)>0$ must be satisfied. But by the above argument, such a point must lie to the southwest of the federalist steady-state equilibrium.

The proposition is illustrated in Figure 1. Note that, because the signs of $B_{k}^{u}$ and $B_{e}^{u}$ can be shown to be ambiguous in general (see below), no general statement is possible regarding the slope of the $B^{u}$ locus and the uniqueness of the unitary steady state, even though the figure shows the locus as downward sloping. While more than one such equilibrium may therefore 
exist, Proposition 1 says that any equilibrium must lie to the southwest of the federalist equilibrium.

The federalist equilibrium is unique, however, when the utility weight $\beta$ on the public good is sufficiently small. To understand this conclusion, note that the unitary solution approaches the federalist solution as $\beta$ approaches zero. In particular, inspection of (20)-(23) shows that each of the four variables $\Delta, \Gamma, \Omega$ and $\Phi$ approaches unity as $\beta$ goes to zero, which implies that $B^{u}(k, e)$ in (24) approaches $B^{f}(k, e)$ in (12). The same convergence occurs with the derivatives $B_{k}^{u}$ and $B_{e}^{u}$, which approach the negative derivatives $B_{k}^{f}$ and $B_{e}^{f}$ as $\beta$ goes to zero. With $B_{k}^{u}$ and $B_{e}^{u}$ thus negative when $\beta$ is sufficiently small, it follows that, under this condition, the $B^{u}$ locus is downward sloping and the unitary equilibrium is unique.

To understand the intuition underlying Proposition 1, consider the $z$ solutions from above. Recall that the unitary $z_{t}$ solution from (17) satifies $z_{t}^{t}<z_{t}<z_{t}^{t-1}$, where $z_{t}^{t}$ and $z_{t}^{t-1}$ are the time- $t$ public consumption levels of the young and old under federalism, from (6) and (8). This comparison assumes common values for the remaining variables in the formulas. Updating this set of inequalities one period yields $z_{t+1}^{t+1}<z_{t+1}<z_{t+1}^{t}$. Combining these results then implies that, conditional on the other variables, the unitary system gives an individual more $z$ than the federalist system when he is young $\left(z_{t}>z_{t}^{t}\right)$ and less $z$ when he is old $\left(z_{t+1}<z_{t+1}^{t}\right)$. With head taxes moving in step, after-tax income is thus lower (higher) in the young (old) period of life under the unitary system than under federalism for given levels of the other variables (including saving). Thus, with the time path of after-tax income ascending more steeply for a given level of saving, it follows that the optimal level of saving under the unitary system must be smaller, as seen in the above comparison of the $B^{f}$ and $B^{u}$ functions (their first two terms are proportional to saving). ${ }^{3}$

As explained in the introduction, adjustments that offset this lower incentive to save are required to maintain equilibrium in the market for physical capital. One adjustment comes from a reduction in $e$, which raises income while young while reducing income in old age. By flattening the ascending income path, this change restores part of the incentive to save, helping to restore equilibrium. Its byproduct, though, is a reduction in economic growth. An additional adjustment is the decline in $k$, which reduces the required volume of saving. 
It should be noted that Proposition 1 is sensitive to the form of the tax system used to support public spending. In particular, the growth impact of fiscal federalism turns out to be ambiguous under a proportional income tax system. ${ }^{4}$ Nevertheless, federalism's clear impact under head taxation is noteworthy.

\subsection{Comparative statics}

Turning to a comparative-static question, recall that the level of the public good chosen under the unitary system depends on the weighting parameter $\theta$, which determines the relative influences of the young and old in that choice (see (15) and (16)). An interesting question then concerns the effect of changing $\theta$ on the rate of economic growth under the unitary system. To investigate this issue, note first that $B_{\theta}^{u}(k, e ; \theta)$ is positive, a conclusion that follows from

the inequalities $\partial \Omega / \partial \theta>0$ and $\partial \Phi / \partial \theta<0$ along with inspection of (24). ${ }^{5}$ If, in addition, $B_{e}^{u}$ is negative, then the $B^{u}$ locus shifts up as $\theta$ increases (the derivative $\partial e / \partial \theta=-B_{\theta}^{u} / B_{e}^{u}$ is positive). But if $B_{k}^{u}$ is also negative, then the $B^{u}$ locus is downward sloping, which means that its upward shift raises the equilibrium values of both $k$ and $e$. Since $B_{e}^{u}$ and $B_{k}^{u}$ are negative from above when $\beta$ is sufficiently small, the following result emerges:

Proposition 2. If $\beta$ is sufficiently small, then giving more weight to the young in the choice of $z$ under the unitary system (raising $\theta$ ) increases the steady-state values of both $k$ and e, leading to faster economic growth.

Thus, the growth penalty inherent in the unitary system is smaller when the young have a greater influence in the choice of $z$ under that system. Although this result may seem natural, the growth impact of $\theta$ is quite indirect, like the link between federalism and growth. To understand this impact, observe from (17) that an increase in $\theta$ reduces $z_{t}$, holding savings constant, by putting more weight on the smaller first term in brackets, which applies to the young. But by updating (17) one period and focusing on the steady state, it can be seen that $z_{t+1}$ falls by a larger amount when $\theta$ increases, given that growth widens the disparity between young and old terms in (17) in the subsequent period. As a result, for a given level of saving, an increase in $\theta$ reduces after-tax income in both periods but does so by more in old age, increasing the incentive to save. The optimal level of saving then rises with $\theta$, which in 
turn requires offsetting increases in both $e$ and $k$ to maintain equilibrium, as in the previous explanation.

\section{Conclusion}

The analysis in this paper suggests that faster economic growth may constitute an additional benefit of fiscal federalism beyond those already well recognized. This result, which matches the conjecture of Oates (1993) and the expectations of most empirical researchers who have studied the issue, arises from an unexpected source: a greater incentive to save when public-good levels are tailored under federalism to suit the differing demands of young and old consumers. This effect grows out of a novel interaction between the rules of public-good provision, which apply cross-sectionally at a given time and involve the young and old consumers of different generations, and the savings decision of a given generation, which is intertemporal in nature. This cross-sectional/intertemporal interaction yields the link between federalism and economic growth.

While it is encouraging that the paper's results match recent empirical findings showing a positive growth impact from fiscal decentralization, additional theoretical work exploring other

possible sources of such a link is clearly needed. The present results emerge from a model based on very minimal assumptions, but exploration of richer models may also be fruitful. 


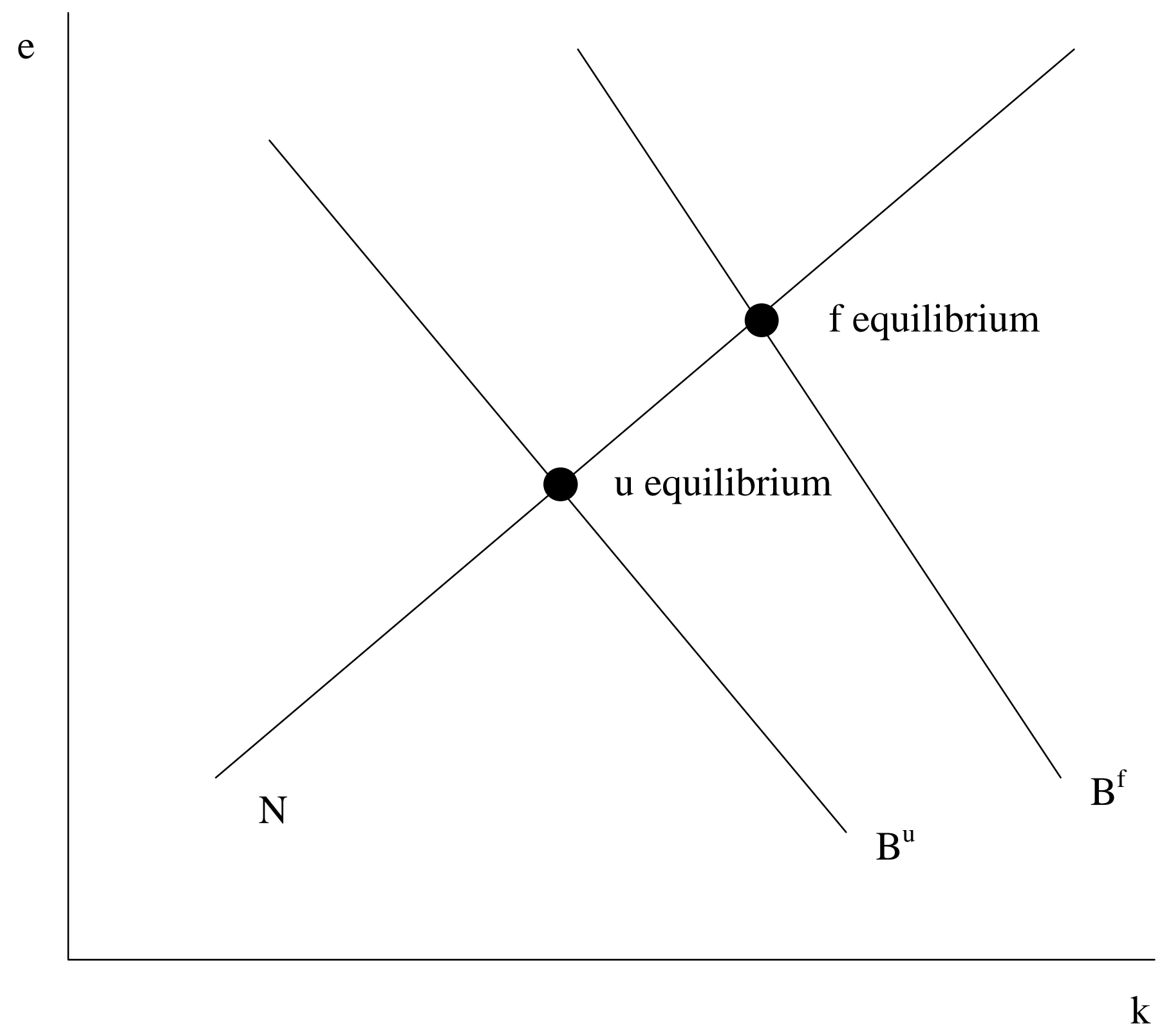

Figure 1: Steady-state equilibria 


\section{References}

Akai, N., Sakata, M., 2002. Fiscal decentralization contributes to economic growth: Evidence from state-level cross section data for the United States, Journal of Urban Economics 52, 93-108.

Alesina, A., Spoalore, E., 1997. On the number and size of nations, Quarterly Journal of Economics 112, 1027-1056.

Besley, T., Conte, S., 2003. Centralized versus decentralized provision of local public goods: a political economy approach, Journal of Public Economics 87, 2611-2637.

Brueckner, J.K., 1999. Fiscal federalism and capital accumulation, Journal of Public Economic Theory 1, 205-224.

Brueckner, J.K., 2004. Fiscal decentralization with distortionary taxation: Tiebout vs. tax competition, International Tax and Public Finance 11, 133-153.

Davoodi, H., Zou, H., 1998. Fiscal decentralization and economic growth: A cross-country study, Journal of Urban Economics 43, 244-257.

Diamond, P.A., 1965. National debt in a neoclassical growth model, American Economic Review 55, 1125-1150.

IImI, A., 2005. Decentralization and economic growth revisited: An empirical note, Journal of Urban Economics 57, 449-461.

Lin, J.Y., LiU, Z., 2000. Fiscal decentralization and economic growth in China, Economic Development and Cultural Change , 49, 1-21.

OAtes, W.E., 1972. Fiscal Federalism (Harcourt Brace Jovanovich, New York).

OAtes, W.E., 1993. Fiscal decentralization and economic development, National Tax Journal $46,237-243$.

OAtes, W.E., 1999. An essay on fiscal federalism, Journal of Economic Literature 37, 11201149.

Stansel, D., 2005. Local decentralization and economic growth: A cross-sectional examination of US metropolitan areas, Journal of Urban Economics 57, 55-72.

Strumpf, K., Rhode, P., 2003. Assessing the importance of the Tiebout hypothesis: Local 
heterogeneity from 1850 to 1990, American Economic Review 93, 1648-1677.

Tiebout, C.M., 1956. A pure theory of local expenditures, Journal of Political Economy 64, 416-424.

Wildasin, D.E., 1986. Urban public finance (Harwood Academic Publishers, Chur, Switzerland).

Xie, D., Zou, H., Davoodi, H., 1999. Fiscal decentralization and economic growth in the United States, Journal of Urban Economics 45, 228-239.

YAkita, A., 2003. Taxation and growth with overlapping generations, Journal of Public Economics 87, 467-487.

Zhang, T., Zou, H., 1998. Fiscal decentralization, public spending and economic growth in China, Journal of Public Economics 67, 221-240. 


\section{Footnotes}

${ }^{*}$ I thank Bill Branch, Ami Glazer, Kangoh Lee and Laudo Ogura for helpful comments. Any shortcomings in the paper, however, are my responsibility.

${ }^{1}$ For overviews of the literature on fiscal federalism, see Wildasin (1986) and Oates (1999).

${ }^{2} B_{e}^{f}<0$ is established by computing the derivative and eliminating terms using (12) to reach a negative expression. From (12), $B_{k}^{f}$ is equal to

$$
\frac{1+\rho}{2+\rho} \frac{\phi f^{\prime \prime}}{f^{\prime 2}}-(2-e) \phi\left(\frac{1}{w}+\frac{k^{2} f^{\prime \prime}}{w^{2}}\right)
$$

using $w^{\prime}=-k f^{\prime}$. After eliminating terms using (12) and carrying out some extensive manipulations, the above expression reduces to

$$
B_{k}^{f}=-(2-e) \frac{\phi}{w}-\frac{(1+\rho)(1-e)}{2+\rho} \frac{f f^{\prime \prime}}{w f^{\prime}}\left[\frac{k}{1+\rho} \frac{f^{\prime}}{f}-\frac{\phi}{(1-e) f^{\prime}}\right] .
$$

(these derivations are not in Yakita's paper but were provided by him on request). As shown by Yakita, saddle-path stability of the steady state is ensured by negativity of the term in brackets in $(f 1)$, which also yields $B_{k}^{f}<0$. Computing $B_{k}^{u}$ yields an expression like that in $(f 1)$, which is negative under the stability condition, along with a second expression that captures the effect of $k$ on the $\Omega$ and $\Phi$ factors in (12). This second expression is positive, making the entire derivative ambiguous in sign, an ambiguity that cannot be resolved by further manipulations. However, since the second expression converges to zero as $\beta$ approaches zero, negativity of $B_{k}^{u}$ is ensured under these circumstances. Similar discussion applies to $B_{e}^{u}$.

${ }^{3}$ It should be noted that this argument relies on additive separability of the utility function, which means that adjustment of $z$ does not affect the marginal utility of $x$, ruling out feedback effects on the incentive to save. The analysis of Brueckner (1999), which assumed general preferences, required $z$ and $x$ to be weak complements in order to generate determinate results.

${ }^{4}$ For simplicity, the income tax is only levied on wage income, excluding the interest income of the old. While income taxation has no effect under federalism given that income taxes are equivalent to head taxes in a homogeneous jurisdiction, it makes a difference under the unitary system. First, it can be shown that, since the young at time $t$ pay a smaller share of public-good cost under income taxation, their demand for $z$ exceeds the federalist level $z_{t}^{t}$ in (6), while the $z$ demand of the old at time $t$ falls short of the federalist level $z_{t}^{t-1}$ in 
(8). Next suppose, that the unitary $z_{t}$ under income taxation is set equal to a $\theta$-weighted average of these demanded $z$ 's, as in (17). Then, it can be shown that, in the steady state, the time- $t$ tax burden on the young equals $\theta c z_{t}^{t}+(1-\theta)(1-e) c z_{t}^{t-1}$, while the time- $t$ tax burden of the old equals $\theta c z_{t}^{t} /(1-e)+(1-\theta) c z_{t}^{t-1}$. Note that these expressions are not weighted averages because of the presence of the $(1-e)$ terms, which appear because of unequal cost shares under income taxation. This fact in turn implies that, at time $t$, the young's tax burden bears an ambiguous relationship to $c z_{t}^{t}$, their burden under federalism, while the tax burden on the old similarly bears an ambiguous relationship to $c z_{t}^{t-1}$ (these conclusions also hold in the next period). Therefore, unlike in the head-tax case, the unitary system need not impose a higher tax burden on the young at time $t$ and a lower burden on the old at time $t+1$, relative to the federalist system. As a result, the unitary system's effect on saving, and hence on economic growth, is ambiguous.

${ }^{5}$ It is easily seen that $\partial \Omega / \partial \theta$ has the same sign as

$$
-\left(\frac{1+\rho}{f^{\prime}(k)} \phi(e)-1\right)\left(\frac{f^{\prime}(k)}{1+\rho} \frac{1}{\phi(e)}-1\right) \frac{\alpha \beta}{(\alpha+\beta)^{2}}>0
$$

while $\partial \Phi / \partial \theta$ has the opposite sign. 